\title{
DETERMINASI KEPUASAN MAHASISWA KELAS INTERNASIONAL IIB DARMAJAYA LAMPUNG
}

\author{
Betty Magdalena ${ }^{1}$, Viola De Yusa ${ }^{2}$ \\ Fakultas Ekonomi dan Bisnis, Institut Informatika dan Bisnis DarmajayaJl. Z.A. Pagar Alam No.93 \\ Labuhan Ratu, Bandar Lampung 35142 Telp. (0721) 700261, 781310 \\ bettymagdalena1969@gmail.com ${ }^{1}$, violadeyusa@darmajaya.ac.id ${ }^{3 \not}$
}

\begin{abstract}
ABSTRAK
Dalam menjaring mahasiswa kelas internasional, IIB Darmajaya berusaha memberikan yang terbaik untuk memenuhi kepuasan mahasiswa. Bahasa Inggris merupakan kewajiban bagi mahasiswa kelas internasional dalam setiap mata kuliah yang diberikan, dan mereka harus lulus dari mata kuliah tersebut. Penelitian ini bertujuan untuk mengetahui faktor-faktor yang menentukan kepuasan siswa kelas internasional IIB Darmajaya dan untuk mengetahui faktor-faktor apa saja yang paling dominan dalam kepuasan siswa kelas internasional. Populasi dalam penelitian ini adalah mahasiswa aktif IIB Darmajaya. Metode pengambilan sampel yang digunakan dalam penelitian ini adalah non-probability sampling dengan menggunakan teknik purposive sampling sehingga diperoleh sampel sebanyak 100 responden. Alat analisis yang digunakan dalam penelitian ini adalah analisis deskriptif. Hasil Importance Performance Analysis menunjukkan atribut penting berikut yaitu mengenai mahasiswa yang bermasalah, dosen/karyawan dapat menyelesaikan masalah, jurusan selalu mencari tahu apa yang dibutuhkan mahasiswa. Mahasiswa merasa aman dengan nilai akhir perkuliahan. Secara umum indeks kepuasan siswa kelas internasional untuk atribut yang diujikan berada pada kriteria cukup memuaskan.
\end{abstract}

Kata kunci: Kepuasan Mahasiswa, Kelas Internasional, Service Quality

\begin{abstract}
In attracting international class students, IIB Darmajaya tries its best to give all the best to meet student satisfaction. English is an obligation for international class students in every given course, and they must graduate from that course. This study aims to determine the factors that determine the satisfaction of international class students of IIB Darmajaya and to determine what factors are the most dominant in the satisfaction of international class students. The population in this study were active students of IIB Darmajaya. The sampling method used in this study is non-probability sampling using a purposive sampling technique to obtain a sample of 100 respondents. The analytical tool used in this study is descriptive analysis. The results of the Importance Performance Analysis show the essential attributes, namely regarding students having problems, lecturers/employees can solve problems, the department always finds out what students need. Students feel safe with the final grades of lectures. In general, the student satisfaction index in the international class for the attributes tested is in the reasonably satisfying criteria.
\end{abstract}

Keywords: Student Satisfaction, International Class, Service Quality

${ }^{2} \rtimes$ Corresponding Author: violadeyusa@darmajaya.ac.id 


\section{PENDAHULUAN}

Perkembangan teknologi saat ini yang terjadi dalam dunia komunikasi menyebabkan banyak bermunculan alat-alat komunikasi yang semakin canggih. Komunikasi pemasaran baru muncul sebagai dialog interaktif antara produsen dan konsumen selama tahap promosi, penjualan, dan pasca penjualan. Dalam hal ini, pelanggan dapat menjangkau produk yang dipasarkan (Kotler \& Keller, 2012). Dalam menjaring calon mahasiswa, persaingan bisnis di bidang jasa pendidikan antar Perguruan Tinggi Negeri/Swasta (PTN/PTS) semakin menantang dan kompetitif. Meningkatnya jumlah perguruan tinggi dari waktu ke waktu mengakibatkan situasi persaingan antar perguruan tinggi khususnya perguruan tinggi swasta semakin tajam. Menurut data (www.pts.co.id), saat ini terdapat kurang lebih 1.465 Perguruan Tinggi Swasta (PTS) di Indonesia yang tersebar dari Sabang hingga Merauke.

Bahasa Inggris saat ini sangat penting untuk dapat bersaing secara global. Sekolah bertaraf internasional mulai dari TK hingga Perguruan Tinggi menjamur meskipun berbiaya mahal. Namun, terdapat banyak tantangan untuk sekolah internasional atau sekolah bilingual. Standar internasional bukan hanya tentang memberikan pelajaran bahasa Inggris atau mengikuti kurikulum dari luar negeri, tetapi lebih tentang bagaimana siswa dapat menerapkan bahasa Inggris dalam kehidupan sehari-hari dan menerapkannya ke kursus (Suryani, 2018).

Bahasa Inggris merupakan kewajiban untuk digunakan bagi siswa internasional kelas IIB Darmajaya dalam setiap mata pelajaran yang diberikan. Mereka harus lulus kursus. Namun karena sebagian besar siswa dari kelas internasional yang berasal dari Indonesia masih menggunakan bahasa Indonesia. Oleh karena itu, mereka tidak terlalu fasih berbahasa Inggris (di kelas) dan tidak memiliki praktik yang baik dalam menggunakan bahasa Inggris. Mereka mengerjakan tugas dan ujian bahasa Inggris dan membuat banyak kesalahan.

IIB Darmajaya merekrut mahasiswa kelas internasional selain berusaha memberikan yang terbaik untuk memenuhi kepuasan mahasiswa. Kepuasan adalah perasaan senang atau kecewa yang membandingkan kinerja dan harapan (Kotler \& Keller, 2012). Kepuasan pelanggan adalah tujuan dan sasaran pemasaran. Perusahaan harus memperhatikan tingkat kepuasan pelanggan seperti halnya mahasiswa Darmjaya kelas internasional IIB. Gambar 1 menunjukkan data jumlah siswa Kelas Internasional IIB Darmajaya.

Berdasarkan data diatas jumlah mahasiswa di kelas internasional dari tahun 2017 sampai dengan tahun 2020 terus mengalami fluktuasi bahkan cenderung mengalami penurunan. Hal ini dapat dilihat pada data jumlah mahasiswa kelas internasional angkatan 2019 mengalami penurunan yang sangat signifikan jika dilihat dari angkatan 2018. Hal ini juga menjadi perhatian yang perlu ditindak lanjuti kenapa jumlah mahasiswa di kelas internasional lebih sedikit dibandingkan dengan kelas reguler dan juga jumlah nya terus mengalami penurunan. Berdasarkan hasil prasurvey yang dilakukan kepada mahasiswa kelas internasional sebanyak 10 orang. Alasan mahasiswa untuk masuk ke kelas internasional yaitu : biaya kuliah, sarana dan prasarana kelas internasional, jarak tempuh kampus, lokasi, akreditasi kampus, tampilan gedung, promo beasiswa, ruangan kelas yang bersih dan nyaman, fasilitas lab kampus yang lengkap, free wifi, kualitas dosen yang mengajar, senior/kakak tingkat yang baik dan saran keluarga atau orang terdekat. 


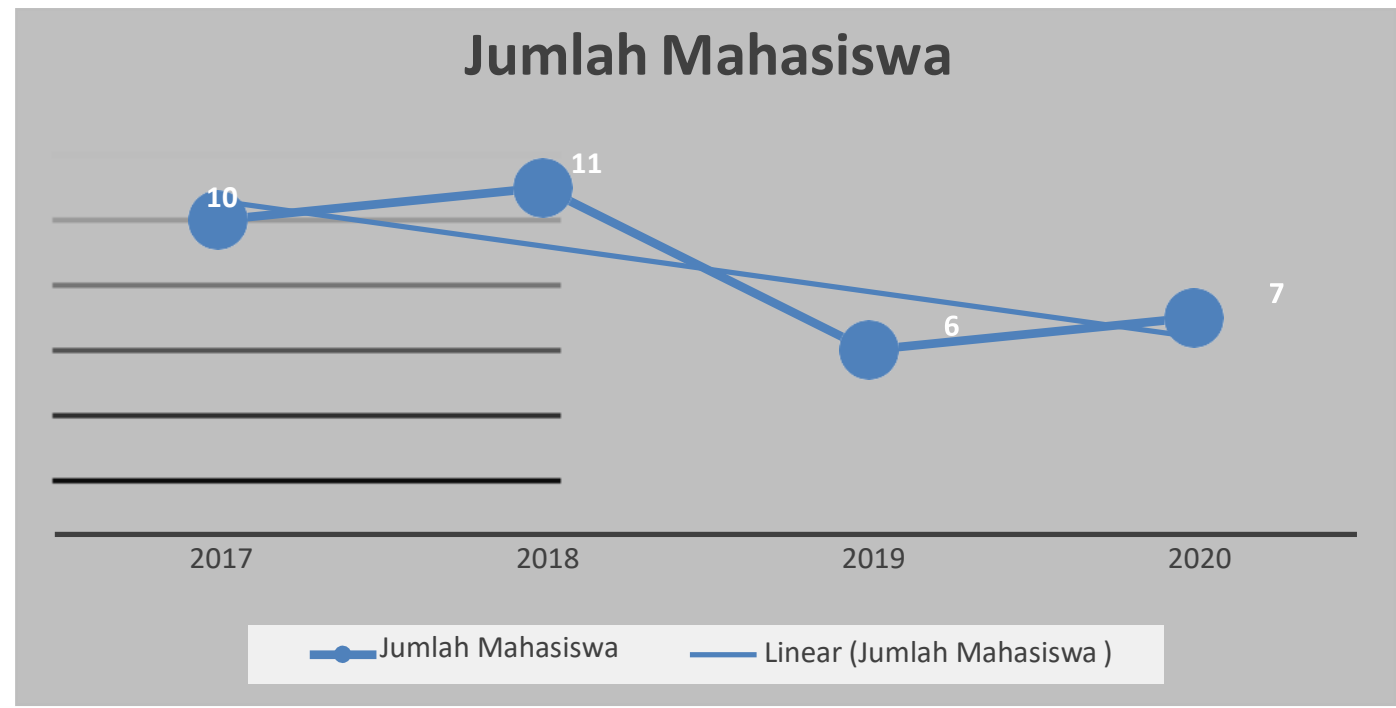

Gambar 1 Jumlah Mahasiswa Kelas Internasional IIB Darmajaya

Sumber : Kelas Internasional IIB Darmajaya

\section{KAJIAN LITERATUR \\ Pemasaran Jasa}

Jasa adalah kegiatan ekonomi yang hasilnya tidak berbentuk fisik atau kontruksi, biasanya dikonsumsi bersamaan dengan waktu jasa tersebut dihasilkan serta memberikan nilai tambah (misalnya: kenyamanan, hiburan, kesenangan atau kesehatan) dapat juga berupa pemecahan atas masalah yang dialami konsumen (Tjiptono, 2011). sebagai produk yang tidak berwujud, seseorang yang membeli jasa, sama artinya dengan menukarkan uang yang dimilikinya dengan suatu produk yang tidak berwujud. Berbeda dengan barang, dimana pembuatan barang dilakukan melewati suatu proses produksi, jasa dihasilkan dari pemberian manfaat suatu atau beberapa sarana maupun prasarana kepada pengguna jasa, dengan penyampaian keterampilan tertentu dari pihak pemberi jasa. Menurut Lupiyoadi (2014) jasa adalah setiap tindakan/kegiatan yang dapat ditawarkan oleh satu pihak kepada pihak lain yang pada dasarnya bersifat intangible (tidak berwujud fisik) dan tidak mengakibatkan kepemilikan apapun. Produksi jasa dapat dikaitkan atau tidak pada satu produk fisik. Dari pengertian diatas, dapat dikatakan bahwa jasa merupakan suatu produk yang tak berwujud, yang berupa tindakan atau kegiatan yang dilakukan oleh penyedia jasa yang dapat dirasakan dan diambil manfaatnya oleh pihak pengguna jasa.

\section{Kepuasan Pelanggan}

Sebagai hal yang sangat penting dalam sebuah perusahaan, hasil penilaian pelanggan terhadap apa yang diharapkan adalah dengan membeli dan mengkonsumsi suatu produk (Aritonang \& Lerbin, 2005). Harapan itu dibandingkan dengan persepsinya terhadap kinerja yang diterimanya dengan mengkonsumsi produk tersebut. Menurut Sunyoto (2013) kepuasan konsumen adalah tingkat perasaan seseorang setelah membandingkan yang dirasakan dibandingkan dengan harapannya. Menurut Kotler \& Keller (2012) kepuasan konsumen adalah tingkat perasaan seseorang setelah membandingkan kinerja atau outcame yang dirasakan dengan harapan-harapan terhadap suatu produk. Menurut Band (1991) Kepuasan pelanggan merupakan tingkatan suatu kebutuhan, keinginan dan harapan dari pelanggan dapat terpenuhi yang akan mengakibatkan terjadinya pembelian ulang atau kesetiaan yang berlanjut. 


\section{Kualitas Pelayanan}

Kualitas Pelayanan merupakan perspektif konsumen dalam jangka panjang serta menjadi evaluasi kognitif konsumen terhadap jasa yang diberikan. Perusahaan yang memberikan komitmen pada kualitas dan secara konsisten memberikan kualitas pelayanan akan menikmati keunggulan persaingan sehingga perusahaan dapat dengan mudah membina loyalitas pelanggan dan membina hubungan pelanggan dengan sukses. Menurut Sviokla (dalam Lupiyoadi, 2014) kualitas pelayanan menjadi suatu keharusan agar dapat mampu bertahan dan tetap mendapat kepercayaan pelanggan. Pola konsumsi dan gaya hidup pelanggan menuntut perusahaan mampu memberikan pelayanan yang berkualitas. Salah satu pendekatan kualitas jasa yang banyak dijadikan acuan dalam riset pemasaran adalah model SERVQUAL (Service Quality)(Lupiyoadi, 2014). Berdasarkan definisi tersebut dapat disimpulkan bahwa kualitas pelayanan adalah kemampuan suatu perusahaan untuk memenuhi keinginan konsumen secara konsisten agar layanan yang diterima melebihi layanan yang diharapkan. Kepuasan pelanggan adalah tingkat perasaan seseorang setelah membandingkan (kinerja atau hasil) yang dirasakan dibandingkan dengan harapannya. Jadi tingkat kepuasan adalah fungsi dari perbedaan antara kinerja yang dirasakan dengan harapan. Konsumen bisa mengalami salah satu dari tiga tingkat kepuasan umun yaitu kalau kinerja sesuai dengan harapan pelanggan akan merasa puas dan bila kinerja bisa melebihi harapan maka, pelanggan akan merasakan sangat puas senang atau gembira.

\section{METODE PENELITIAN}

Penelitian ini menggunakan penelitian deskriptif, yaitu penelitian yang dilakukan untuk mengetahui nilai satu variabel atau lebih (independen) tanpa membuat perbandingan, atau menghubungkan suatu variabel. populasi penelitian ini adalah populasi adalah mahasiswa aktif IIB Darmajaya. Pengambilan sampel dilakukan dengan pertimbangan bahwa populasi yang ada sangat besar jumlahnya, sehingga tidak memungkinkan untuk meneliti seluruh populasi yang ada. oleh karena itudibentuk sebuah perwakilan populasi. Dalam penelitian tidak mungkin mempelajari semua yang ada pada populasi, maka peneliti dapat menggunakan metode nonprobability sampling yaitu dengan menggunakan teknik purposif sampling, yaitu tekhnik untuk menentukan sampel dengan beberapa pertimbangan tertentu yang bertujuan agar menjelaskan pendekatan analisis yang dilakukan, profil responden/kasus, ukuran dan penentuan sampel, metode pengambilan data, operasionalisasi variabel, dan metode analisis data yang diperoleh nantinya lebih reprensentatif (Sugiyono, 2009). Kriteria sampel sebagai berikut:

a. Merupakan mahasiswa aktif IIB Darmajaya .

b. Sudah pernah ikut seleksi penerimaan Kelas International.

\section{HASIL PENELITIAN DAN PEMBAHASAN}

Pada analisis tingkat kepuasan mahasiswa kelas internasional (Gambar 2) dapat diketahui sampai sejauh mana tingkat kinerja atau pelaksaan variabel yang dibahas dapat memenuhi kebutuhan atau harapan dari pelanggan. Variabel yang dibahas adalah indikator dari pelayanan yaitu: tangible, reliability, responsiveness, emphaty dan ansurance. Hasil Importance Performance Analysis menunjukan atribut yang harus diprioritaskan yaitu mengenai mahasiswa memiliki masalah, dosen/karyawan dapat memecahkan masalah, pihak jurusan selalu mencari tahu apa yang dibutuhkan oleh mahasiswa dan mahasiswa merasa aman dengan nilai akhir perkuliahan. Atribut yang harus tetap dipertahankan adalah Dosen/Karyawan berpakaian sopan, bersih dan rapih, Fasilitas perpustakaan yang memadai, Suasana lingkungan kelas bersih dan nyaman, Pelayanan pembayaran dan customer service cepat tanpa keraguan dan pihak jurusan sigap menanggapi pertanyaan atau keluhan 
mahasiswa. Atribut yang prioritas rendah mengenai Kompetensi dosen mengajar menggunakan bahasa inggris, Referensi buku bahan ajar berbahasa inggris minim, Mahasiswa merasa aman dalam proses belajar mengajar dan Dosen maupun karyawan memberikan informasi jelas serta mudah dipahami. Sedangkan untuk atribut yang berlebihan yaitu peralatan laboraturium komputer yang digunakan modern dan berteknologi tinggi, Gambar Walpaper atau bingkai pajangan di dinding tersusun baik dan rapih serta Penilaian kinerja dosen/karyawan yang mengajar dilakukan disetiap semester.

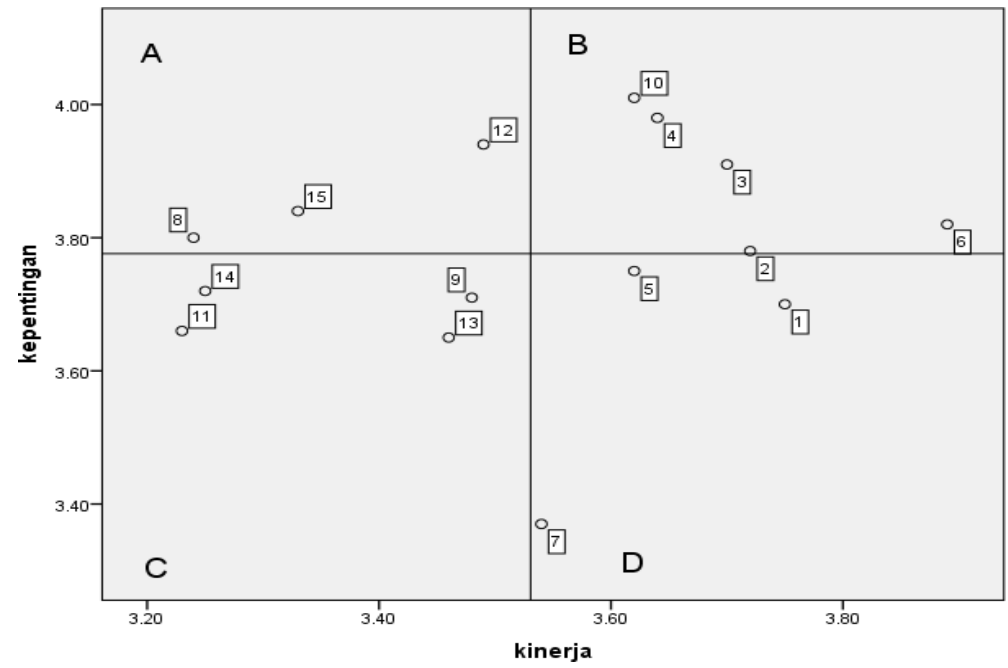

Gambar 2 Diagram Kartesius

Tabel. 1 Perhitungan Customer Satisfaction Index

\begin{tabular}{|l|l|l|l|l|l|}
\hline No. & Atribut & $\begin{array}{l}\text { Kepentingan } \\
\text { mean } \\
\text { importance } \\
\text { score }\end{array}$ & $\begin{array}{l}\text { weighted } \\
\text { faktors }\end{array}$ & $\begin{array}{l}\text { Kean } \\
\text { satisfaction } \\
\text { score }\end{array}$ & $\begin{array}{l}\text { weighted } \\
\text { score }\end{array}$ \\
\hline 1 & Tangible & 3.80 & 0.20 & 3.72 & 0.75 \\
\hline 2 & Reliability & 3.85 & 0.20 & 3.72 & 0.76 \\
\hline 3 & Ressponsivness & 3.63 & 0.19 & 3.42 & 0.66 \\
\hline 4 & Emphaty & 3.87 & 0.20 & 3.45 & 0.71 \\
\hline 5 & Assurance & 3.74 & 0.20 & 3.35 & 0.66 \\
\hline & & $\mathbf{1 8 . 8 8}$ & Weighted Average & $\mathbf{3 . 5 3}$ \\
\hline
\end{tabular}

Sumber: Data diolah,2021

Berdasarkan hasil penelitian kepuasan mahasiswa kelas internasional IIB Darmajaya dapat diketahui bahwa nilai customer satisfaction index (CSI) adalah sebesar 70,60\% atau 0,7060, Jika didasarkan pada indeks kepuasan mahasiswa maka nilai 0,7060 , berada pada range $0,66-0,80$, sehingga dapat dikatakan bahwa secara umum indek kepuasan mahasiswa di kelas internasional untuk atribut-atribut yang diuji ada pada kriteria puas. 


\section{PENUTUP}

Kesimpulan dari penelitian mengenai kepuasan mahasiswa di kelas internasional adalah sebagai berikut. Hasil Importance Performance Analysis menunjukan atribut yang harus diprioritaskan yaitu mengenai Mahasiswa memiliki masalah, dosen/karyawan dapat memecahkan masalah, Pihak jurusan selalu mencari tahu apa yang dibutuhkan oleh mahasiswa dan Mahasiswa merasa aman dengan nilai akhir perkuliahan. Sedangkan untuk atribut yang harus tetap dipertahankan adalah Dosen/Karyawan berpakaian sopan, bersih dan rapih, Fasilitas perpustakaan yang memadai, Suasana lingkungan kelas bersih dan nyaman, Pelayanan pembayaran dan custemer service cepat tanpa keraguan dan Pihak jurusan sigap menanggapi pertanyaan atau keluhan mahasiswa. Atribut yang prioritas rendah mengenai Kompetensi dosen mengajar menggunakan bahasa inggris, Referensi buku bahan ajar berbahasa inggris minim, Mahasiswa merasa aman dalam proses belajar mengajar dan Dosen maupun karyawan memberikan informasi jelas serta mudah dipahami. Sedangkan untuk atribut yang berlebihan yaitu Peralatan laboraturium komputer yang digunakan modern dan berteknologi tinggi, Gambar Walpaper atau bingkai pajangan di dinding tersusun baik dan rapih serta Penilaian kinerja dosen/karyawan yang mengajar dilakukan disetiap semester. Secara umum indeks kepuasan mahasiswa di kelas internasional untuk atribut-atribut yang diuji adalah berada pada kriteria cukup puas.

\section{Saran}

Saran yang bisa disampaikan dari hasil penelitian yang didapat adalah sebagai berikut: Sebagai kampus swasta terbaik di Bandar Lampung IIB Darmajaya harus dapat meningkatkan kualitas pelayanannya secara keseluruhan. Mahasiswa akan merasa puas dengan pelayananan yang diberikan, sehingga dengan memperhatikan atribut-atribut yang dianggap penting oleh mahasiswa dan kinerja prodi kelas internasional juga dapat ditingkatkan.

\section{BIBLIOGRAFI}

Aritonang, R., \& Lerbin, R. (2005). Kepuasan pelanggan: pengukuran dan penganalisisan dengan SPSS. Gramedia Pustaka Utama.

Band, W. A. (1991). Creating Value for Customers: Designing and Implementing a Total Corporate Strategy.

Kotler, P., \& Keller, K. L. (2012). Marketing Management (14th ed.). Prentice-Hall. Lupiyoadi, R. (2014). Manajemen Pemasaran Jasa. Selemba Empat.

Sugiyono. (2009). Metode Penelitian Bisnis. AFABETA.

Sunyoto, D. (2013). Teori, Kuesioner \& Analisis Data Untuk Pemasaran Dan Perilaku Konsumen. Graha Ilmu.

Suryani, D. (2018). Analisis Pengembangan Parawisata Terhadap Kesempatan Kerja Dalam Prespektif Ekonomi Islam (Studi di Pantai Sari Ringgung Kecamatan Teluk Pandan Kabupaten pesawaran).

Tjiptono, F. (2011). Pemasaran Jasa (Pertama). Bayu Media Publishing. 